\title{
Capsulotomia medial
}

\author{
Medial capsulotomy
}

\author{
Paiva Gonçalves Neto \\ Rubens Belfort $\mathbf{J r}^{2}$
}

\section{RESUMO}

Objetivo: Avaliar os benefícios de uma técnica alternativa de capsulotomia anterior, criada para garantir a completa implantação da lente intra-ocular no saco capsular, durante a extração extracapsular da catarata. Métodos: Cento e nove olhos foram operados por meio dessa técnica e acompanhados durante o período de 1 ano. As possibilidades da técnica foram avaliadas em relação a dois aspectos: a garantia de perfeita colocação da lente no saco capsular e a capacidade de promover eficiente fixação do implante, por meio das características apresentadas pelas porções remanescentes da cápsula anterior. $\mathrm{O}$ primeiro aspecto foi analisado considerando o número de casos em que as duas abas puderam ser adequadamente observadas durante a implantação. $\mathrm{O}$ segundo aspecto foi avaliado em função do posicionamento da lente, 1 ano após a cirurgia. Dificuldades e complicações específicas dessa técnica foram também, investigadas. Resultados: Durante a implantação, as duas abas puderam ser adequadamente identificadas em $96(90,6 \%)$ casos. Um ano após a cirurgia, a lente se encontrava centralizada em $81,9 \%$ dos casos, discretamente descentralizada (menos de $1 \mathrm{~mm}$ ), em 13,3\% e descentralizada (mais de $1 \mathrm{~mm}$ ) em 4,8\%. Conclusões: Esses resultados, quando comparados aos apresentados em relação a outros tipos de capsulotomia, indicam que essa técnica é boa alternativa para promover a adequada implantação da lente no saco capsular, na extração extracapsular da catarata.

Descritores: Extração da catarata; Implantação de lente intra-ocular/métodos; Capsulotomia; Intercapsular; In the bag; Catarata, cápsula, cristalino; Implantação, lente, intraocular; Alterações visuais

\section{INTRODUÇ̃̃̃O}

Implantar a lente intra-ocular perfeitamente dentro do saco capsular é algo que, nos dias de hoje, se faz de forma absolutamente natural. No entanto, nem sempre foi tão simples assim. Houve época em que terminar a cirurgia com toda a lente atrás da íris já era um grande feito. Pouco importava em que parte da câmara posterior suas alças viriam a encontrar apoio. Colocá-las no saco capsular, ou no sulco ciliar, dependia quase que exclusivamente do acaso ${ }^{(1-3)}$. Na verdade, o que mais comumente ocorria, era acabar com uma delas no interior do saco e a outra, fora dele ${ }^{(4-7)}$.

Não demorou a que se descobrisse que o inadequado posicionamento da lente era a causa de uma série de complicações ${ }^{(8-17)}$ e, a partir de então, passou-se a ter o cuidado de procurar colocá-la totalmente dentro do saco capsular $^{(18)}$. Algo, diga-se de passagem, que não dependia apenas da determinação do cirurgião, levando-se em conta o tipo de capsulotomia anterior então usado ("abridor de latas").

Variações no formato da abertura da cápsula ${ }^{(19)}$, técnicas especiais para introduzir as alças ${ }^{(20-26)}$ e o surgimento da substância visco-elástica ${ }^{(27-28)}$, 
muito ajudaram nesse empenho. No entanto, foi somente depois do aparecimento das capsulotomias em dois tempos, que se passou a ter uma verdadeira garantia quanto à colocação da lente no espaço intercapsular.

Esses métodos fundamentavam-se na realização de uma abertura linear ${ }^{(29)}$ - ou arqueada ${ }^{(30)}$ - entre os terços superior e médio da área pupilar. Desse modo, a implantação era conduzida sob uma perfeita observação dos limites capsulares e, depois de colocada a lente, a porção central da cápsula anterior era recortada e removida, de modo a deixar livre o eixo visual.

Durante um longo tempo, utilizamos essas técnicas com ótimos resultados. Aos poucos, porém, passamos a realizar a incisão da cápsula cada vez mais perto do centro da área pupilar. Até notarmos que a segunda etapa da capsulotomia já não era necessária.

Havíamos com isso eliminado um delicado tempo da operação, sem perder, contudo, as vantagens do método original. Pelo contrário, a disposição simétrica das abas melhor definia os limites capsulares; reduzia o risco do "flap" superior vir a desaparecer durante a retirada do núcleo e, através desses benefícios, dava-nos maior garantia quanto à completa implantação da lente no saco capsular.

Quanto aos inconvenientes, jamais observamos o que muitos diziam temer, a propagação do corte até a cápsula posterior. Não chegamos também a registrar qualquer inconveniente relacionado à estreita abertura que havia entre as duas abas, durante a cirurgia. Na verdade, ela acabava se alargando em conseqüência da retração produzida pelo processo cicatricial. Em todos os aspectos, o que obtínhamos com esse tipo de capsulotomia, muito se assemelhava ao que hoje nos proporciona a abertura contínua da cápsula anterior (capsulorrexis).

Apesar de termos apresentado tal idéia há muito tempo, ainda hoje nos perguntam sobre alguns aspectos da técnica. Por isso, achamos oportuno publicar as principais observações de nosso trabalho original, o qual foi apresentado como tese para a obtenção do título de mestre em oftalmologia na Escola Paulista de Medicina.

\section{MÉTODOS}

O estudo incluiu 102 pacientes (109 olhos), dos quais 37 $(36,3 \%)$ pertenciam ao sexo masculino e $65(63,7 \%)$ ao feminino, com idades que variavam de 9 a 90 anos, a partir de um valor médio de 65 anos.

Nenhuma seleção quanto à localização, intensidade e natureza da opacificação foi levada em conta, tendo sido incluídos, além dos $101(97,7 \%)$ casos de origem senil (com diferentes graus de comprometimento do cristalino), $5(4,6 \%)$ cataratas congênitas e $3(2,7 \%)$ metabólicas. Apesar de se ter procurado evitar as alterações oftalmológicas que de praxe são excluídas, não foram descartados os casos em que uma cirurgia combinada se fazia necessária. Condição em que se encontravam $5(4,6 \%)$ dos pacientes estudados. Não se deixou também de incluir $4(3,7 \%)$ indivíduos, previamente submetidos à cirurgia fistulizante.
Técnica cirúrgica - As operações foram realizadas na Santa Casa de Misericórdia do Rio de Janeiro, entre 27 de junho de 1989 e 10 de abril de 1990.

Depois de concluídos os tempos iniciais da operação, a capsulotomia anterior era realizada tomando-se o cuidado de produzir uma incisão perfeitamente reta. Para isso, usava-se, ao invés de cortes, simples puncturas. A ponta do cistítomo era apenas pressionada contra a cápsula anterior, sem que qualquer outro movimento fosse a ele aplicado.

Partindo das $3 \mathrm{~h}$, tais puncturas eram feitas de modo a deixar entre elas finas traves de cápsula (Figura 1), as quais serviam para impedir que essa membrana, inadvertidamente, se rompesse às custas de sua elasticidade. Após chegar ao outro extremo da abertura $(9 \mathrm{~h})$, percorria-se a incisão em sentido contrário, seccionando as traves de cápsula que inicialmente haviam sido deixadas (Figuras 2 e 3 ).

Quando diante de uma catarata, cujo grau de transparência era capaz de impedir a adequada observação da cápsula anterior, passava-se a realizar a capsulotomia do centro para os lados. Desta feita, uma trave central de aproximadamente $2 \mathrm{~mm}$ era mantida intacta, até que as incisões laterais fossem terminadas. Só a partir de então, concluía-se, cuidadosamente, a abertura.

Em qualquer das duas situações, entretanto, a capsulotomia era realizada até os limites determinados pela borda da pupila, sob ampla midríase. Nos casos em que não se obtinha tamanha dilatação, era ainda possível criar uma abertura igualmente extensa, trabalhando-se por debaixo da íris. Quando menor do que $6 \mathrm{~mm}$, a pupila era alargada por meio de uma iridotomia radial (com posterior sutura da íris).

Em seguida, por sob as duas porções de cápsula criadas pela capsulotomia, realizava-se a injeção de solução salina balanceada, de modo a romper as adesões corticais. Utilizando a

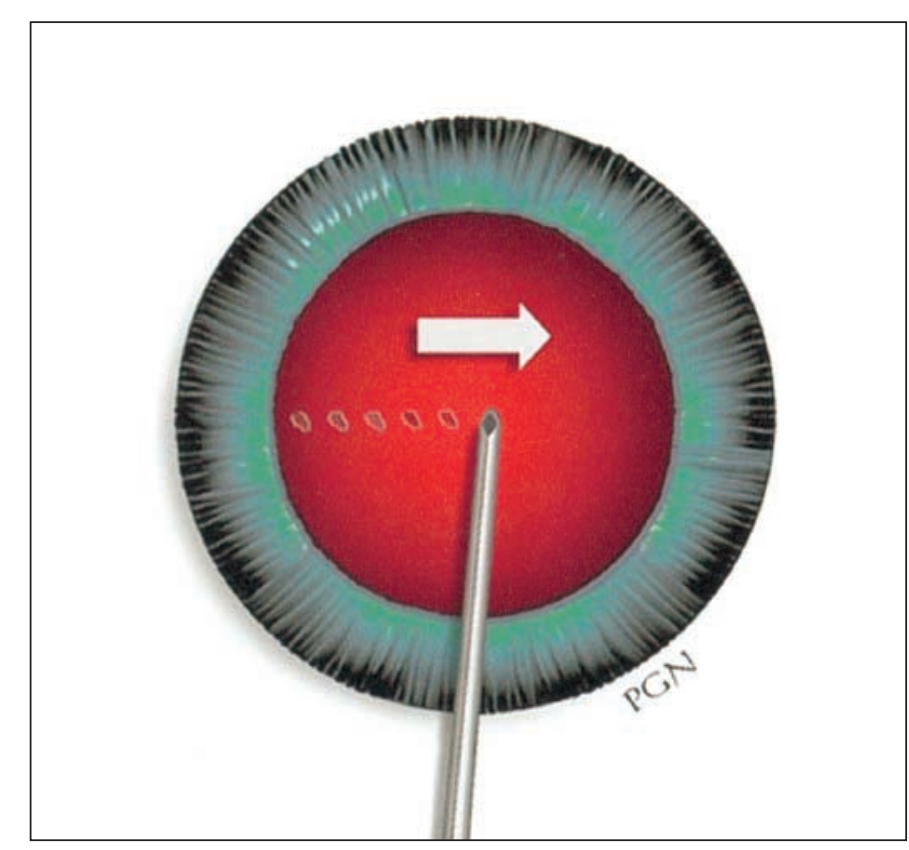

Figura 1 - Simples puncturas são feitas de 3 às $9 \mathrm{~h}$ 
manobra de pressão e contra-pressão, prosseguia-se com a extração do núcleo. Não, sem antes observar, ao exercer ligeira pressão sobre o lábio escleral da incisão, o fácil deslizamento dessa estrutura por sob a metade superior da cápsula anterior. Quando assim não ocorria, a remoção do núcleo só era levada a cabo após luxá-lo, com ajuda do cistítomo, para cima da referida porção da cápsula. Procurava-se, de tal modo, evitar que esta se rompesse em conseqüência do emprego de excessiva pressão. Cuidado que passou a ser adotado depois de verificada a ocorrência de tal acidente em alguns dos primeiros casos operados.

No tempo seguinte, a aspiração do córtex cristaliniano era realizada com uma cânula de dupla-via, modelo Simcoe. A dificuldade de aspirar as massas localizadas às $12 \mathrm{~h}$, em conseqüência do maior tamanho da aba superior, era contornada girando-se a cânula por baixo dessa estrutura, até fazer sua ponta atingir tal região.

Com o implante seguro superiormente por uma pinça McPherson, iniciava-se sua introdução, fazendo passar a primeira alça por sob a metade inferior da cápsula anterior (Figura 4). Em seguida, com a ponta da mesma pinça fechada, empurrava-se a lente por sua borda superior, até fazê-la deslizar para baixo da outra metade de cápsula (Figura 5). Desse modo, tinha-se praticamente todo o implante já dentro do saco capsular (Figura 6). A segunda alça era facilmente introduzida, pois o pedaço de cápsula por sob o qual deveria passar (aba superior), encontrava-se adequadamente afastado da cápsula posterior, graças à presença do próprio corpo da lente (Figura 7).

Na maior parte dos casos, o implante foi colocado verticalmente dentro do saco capsular e assim deixado. Em 22 (20,2\%) olhos, entretanto, realizou-se sua rotação até a posição horizontal.

Parâmetros avaliados - Dentre os diferentes aspectos estu-

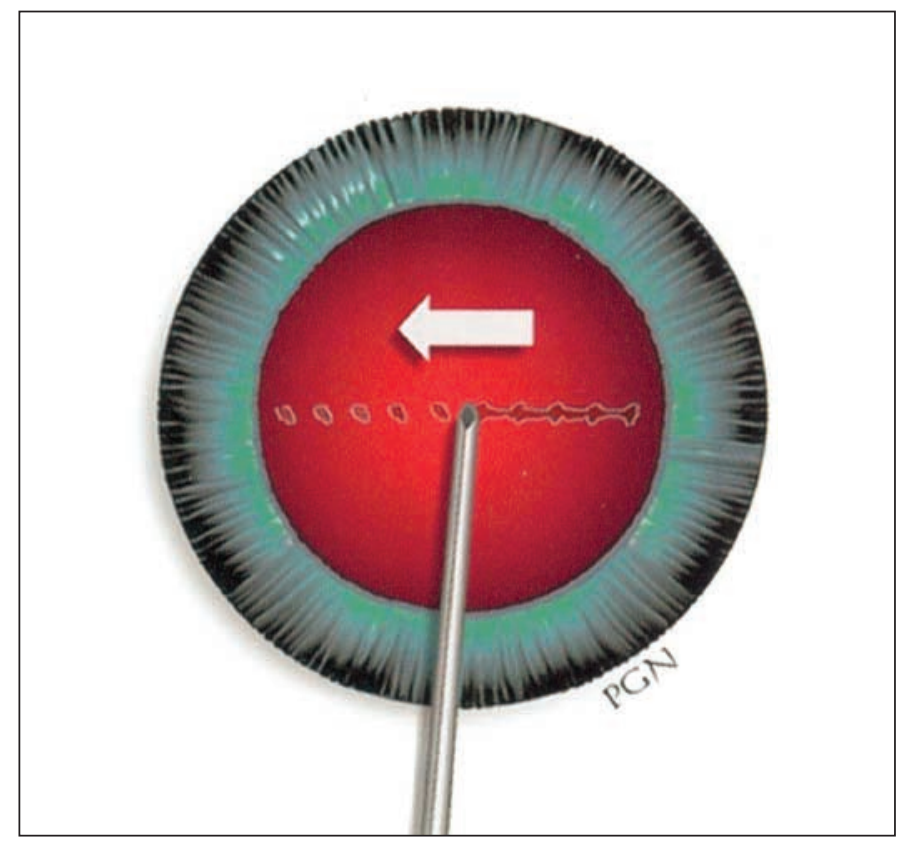

Figura 2 - Em seguida, as traves de cápsula deixadas entre as puncturas, são rompidas

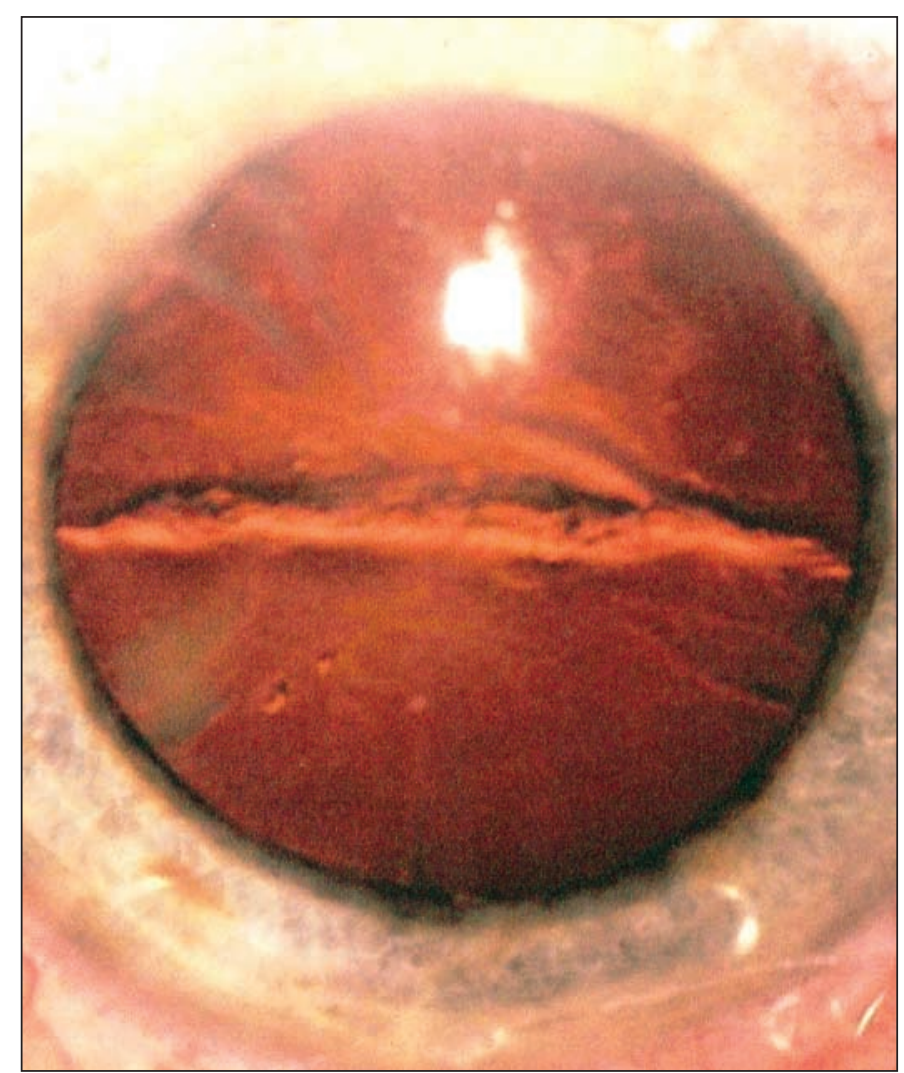

Figura 3 - Desse modo, consegue-se uma incisão bem regular

dados, procurou-se julgar, acima de tudo, as condições criadas para garantir a colocação de toda lente no saco capsular e, em longo prazo, a freqüência com que se conseguiu mantê-la bem posicionada, no interior desse espaço.

O primeiro parâmetro foi investigado em função das condições de observação das duas abas de cápsula anterior, no momento da implantação da lente. Para isso, foram registradas as características apresentadas por esses elementos e o tamanho da abertura existente entre eles (com a ajuda de uma cânula milimetrada). Procurou-se também anotar o diâmetro que a pupila apresentava nessa etapa, o qual foi classificado em três categorias: pequeno (inferior a $6 \mathrm{~mm}$ ), médio (entre 6 e $8 \mathrm{~mm}$ ) e grande (superior a $8 \mathrm{~mm}$ ).

$\mathrm{Na}$ análise do posicionamento definitivo da lente, usou-se o seguinte critério: após dilatar a pupila com tropicamida $1 \%$ e fenilefrina $2,5 \%$ (3 instilações, com intervalos de 15 minutos), identificava-se o maior espaço entre as bordas da pupila e da lente (Figura 8). Em seguida, na lâmpada de fenda (com o aumento de 25x), girava-se a faixa de luz do aparelho até deixála paralela a esses limites. A largura da faixa era então ajustada, de modo a fazê-la ocupar a exata distância entre as duas bordas (Figura 9). Após afastar o paciente da posição de exame, colocava-se uma pequena régua no campo de observação e, sem movimentar o aparelho, procurava-se focar os traços nela existentes (Figura 10). Desse modo, a largura da faixa de luz era medida e, com isso, tinha-se à distância entre as bordas da pupila e da lente. 


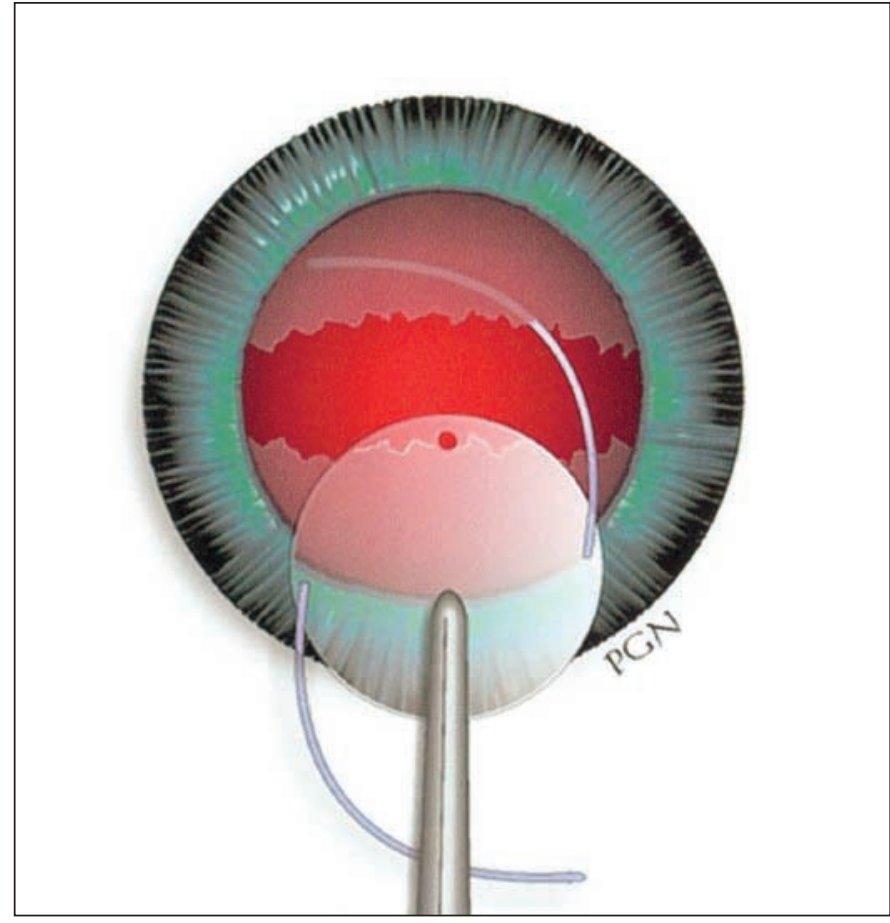

Figura 4 - A primeira alça é colocada sob a aba inferior

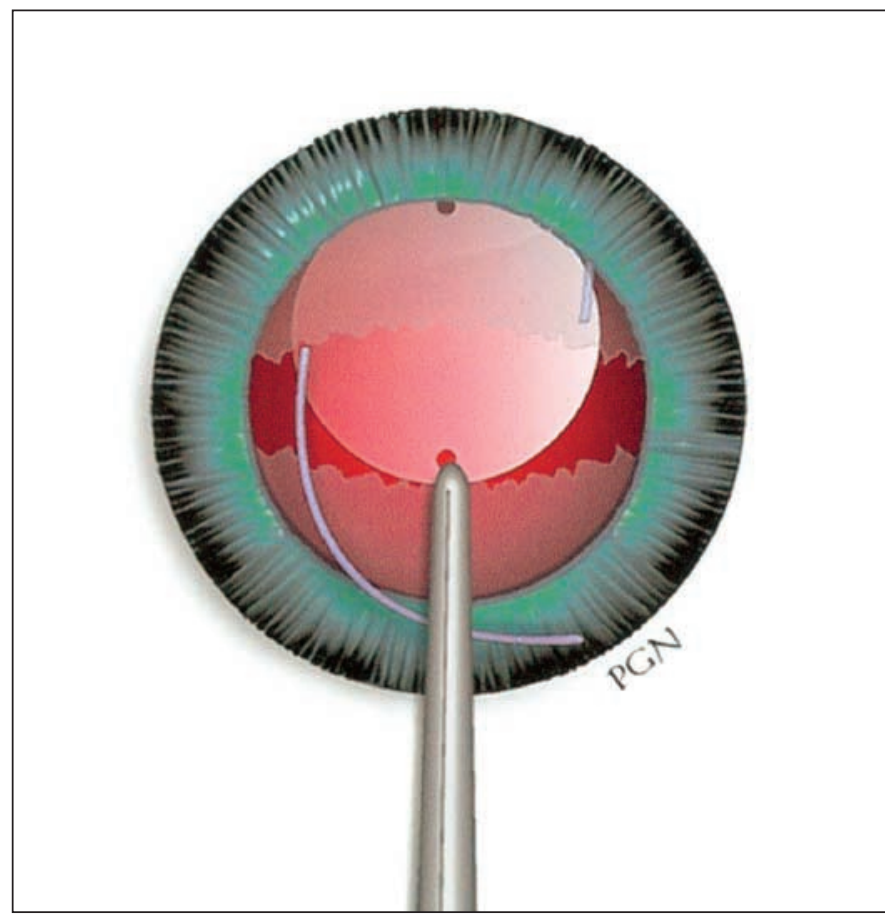

Figura 5 - Com a pinça fechada, o corpo da lente é empurrado para baixo da aba superior

\section{RESULTADOS}

De acordo com a seqüência anteriormente descrita, o primeiro aspecto avaliado refere-se aos métodos empregados na

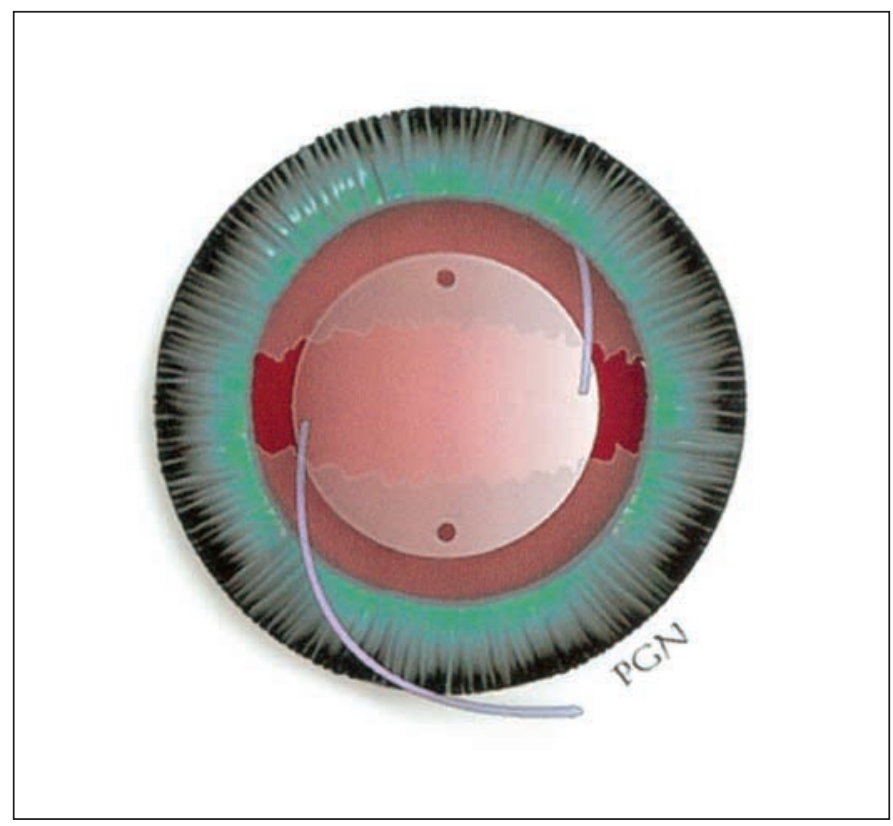

Figura 6 - Com isso, praticamente toda a lente já se encontra dentro do saco capsular

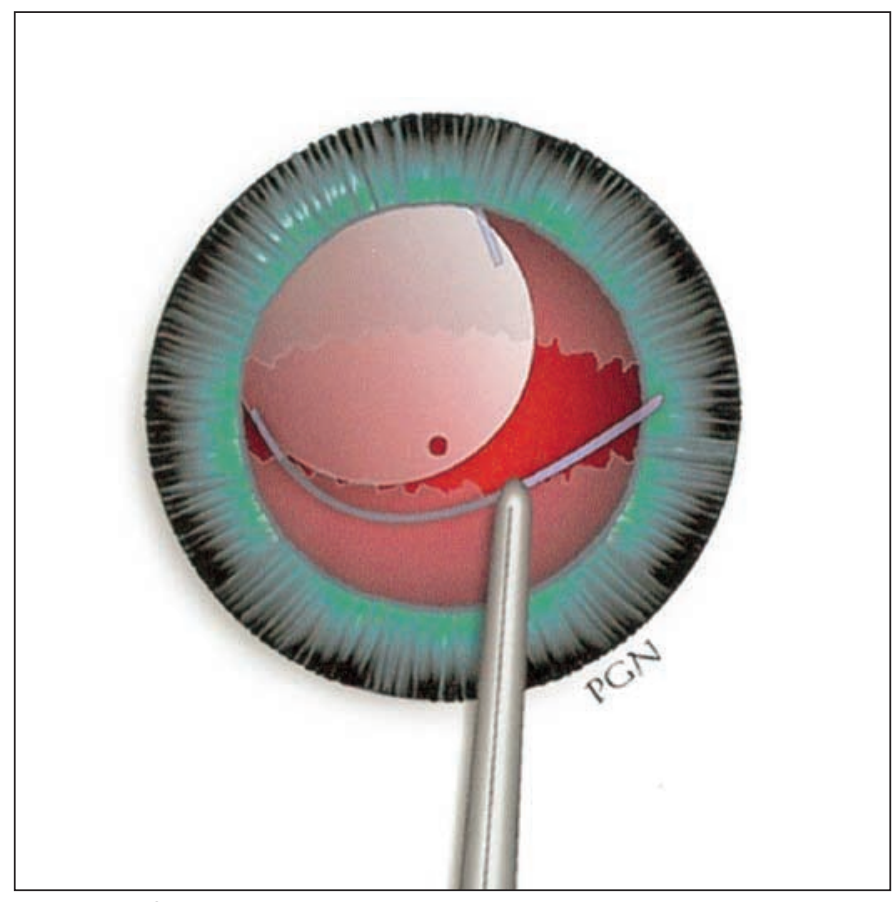

Figura 7 - Com o espaço criado pelo corpo da lente, a segunda alça é fácilmente implantada

realização da capsulotomia. Durante tal etapa, a observação da cápsula anterior encontrou-se prejudicada em 14 (12,8\%) casos, devido ao acentuado grau de opacificação do cristalino. Sob tais circunstâncias, a capsulotomia foi realizada do centro para os lados, conforme já descrito. Nas demais cirurgias $(95-87,2 \%)$, a cápsula foi aberta de um extremo ao outro da área pupilar. 


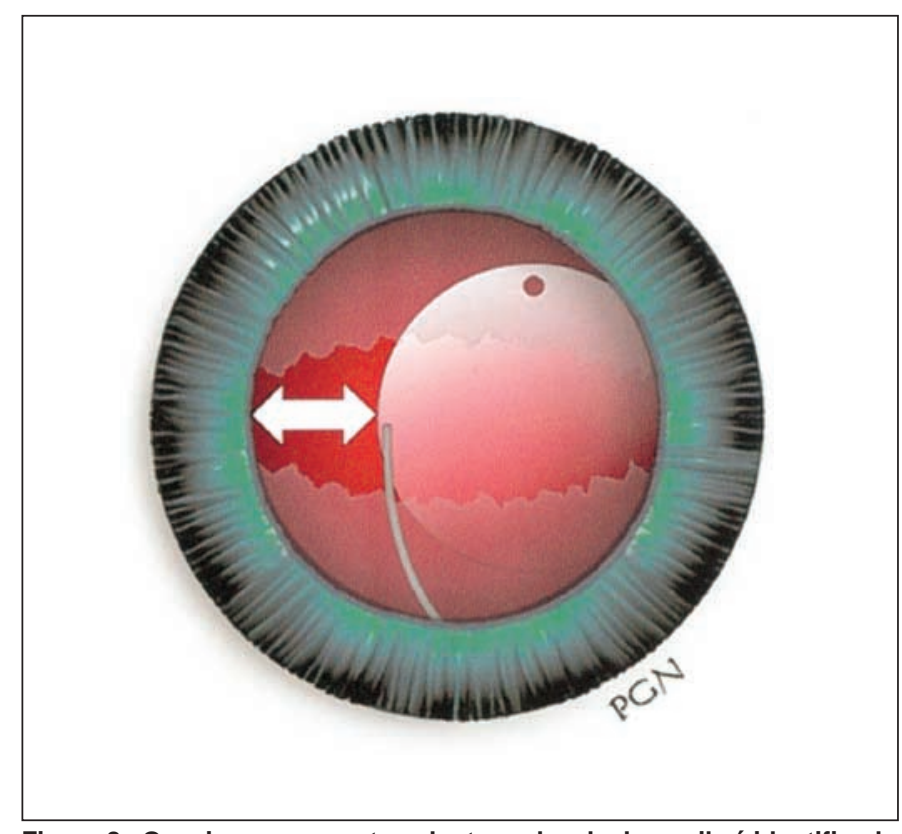

Figura 8 - O maior espaço entre a lente e a borda da pupila é identificado

Para obter uma capsulotomia com aproximadamente $8 \mathrm{~mm}$ de comprimento, foi necessário realizar uma iridotomia radial em $8(7,3 \%)$ casos, nos quais a pupila apresentava menos do que $6 \mathrm{~mm}$ de diâmetro. Nas $23(21,1 \%)$ vezes em que tal diâmetro encontrava-se entre 6 e $8 \mathrm{~mm}$, foi possível obter o desejado comprimento, trabalhando-se por debaixo de uma pequena porção da íris. Nas demais cirurgias (78 - 71,6\%), a capsulotomia foi realizada inteiramente dentro da área pupilar.

No que se refere à manobra de extração do núcleo, foi possível realizá-la em $4(80,0 \%)$ das 5 cataratas congênitas, através de simples aspiração. Tais casos representam 3,7\% do total das cirurgias. Nos demais $(96,3 \%)$, o núcleo foi removido por meio de pressão e contra-pressão, sendo que em 14 (13,3\%) deles, tornou-se necessário luxá-lo previamente com ajuda do cistítomo.

$\mathrm{Na}$ aspiração do córtex, a dificuldade em se alcançar as massas localizadas às $12 \mathrm{~h}$, devido ao grande tamanho da aba superior, foi contornada através da rotação da cânula de dupla-via, conforme já explicado. Em 65 (5,5\%) casos, entretanto, tal manobra não pôde ser adequadamente realizada em conseqüência da ocorrência de uma significativa hipertensão vítrea. Apesar disso, apenas uma pequena porção de córtex acabou não sendo removida, com exceção de um caso, em que praticamente toda a sua metade superior teve de ser deixada.

Tais pacientes foram acompanhados com maior cuidado, tendo um deles desenvolvido uma uveíte anterior de intensidade moderada, a qual foi resolvida sem deixar qualquer seqüela. Num segundo caso, verificou-se uma descentralização lateral do implante, depois de transcorridos 30 dias.

A ruptura da cápsula posterior foi observada em $3(2,7 \%)$ casos, durante a aspiração das massas de 12 h. Nessas três vezes, a lente foi implantada no sulco ciliar. Excluídos esses

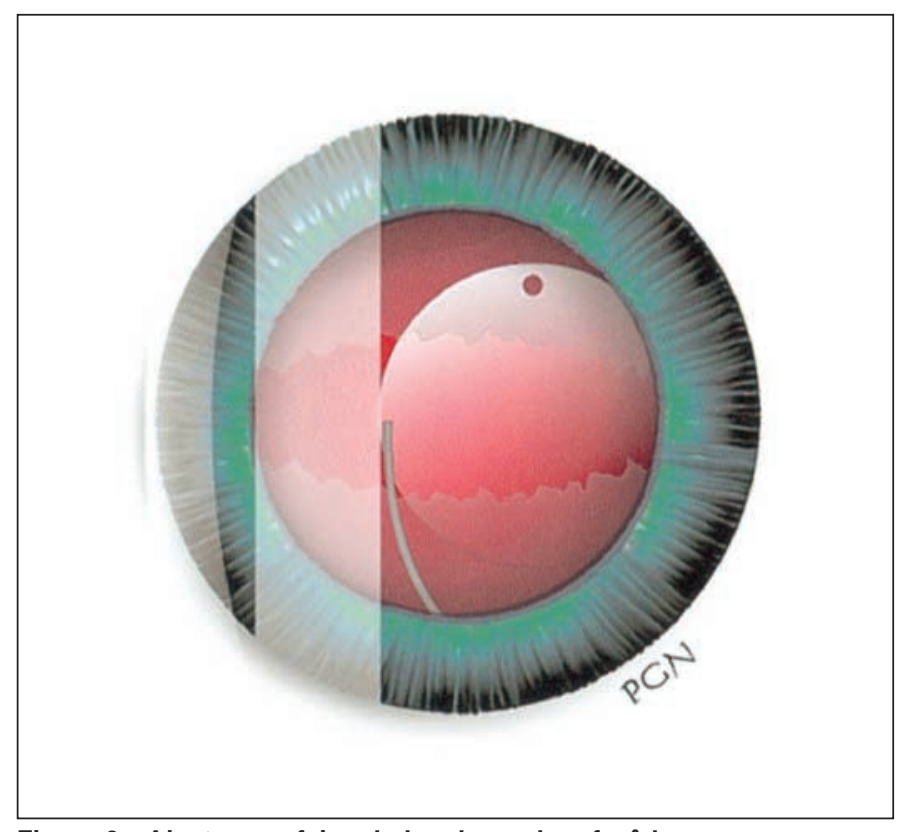

Figura 9 - Ajusta-se a faixa de luz de modo a fazê-la ocupar o espaço antes definido

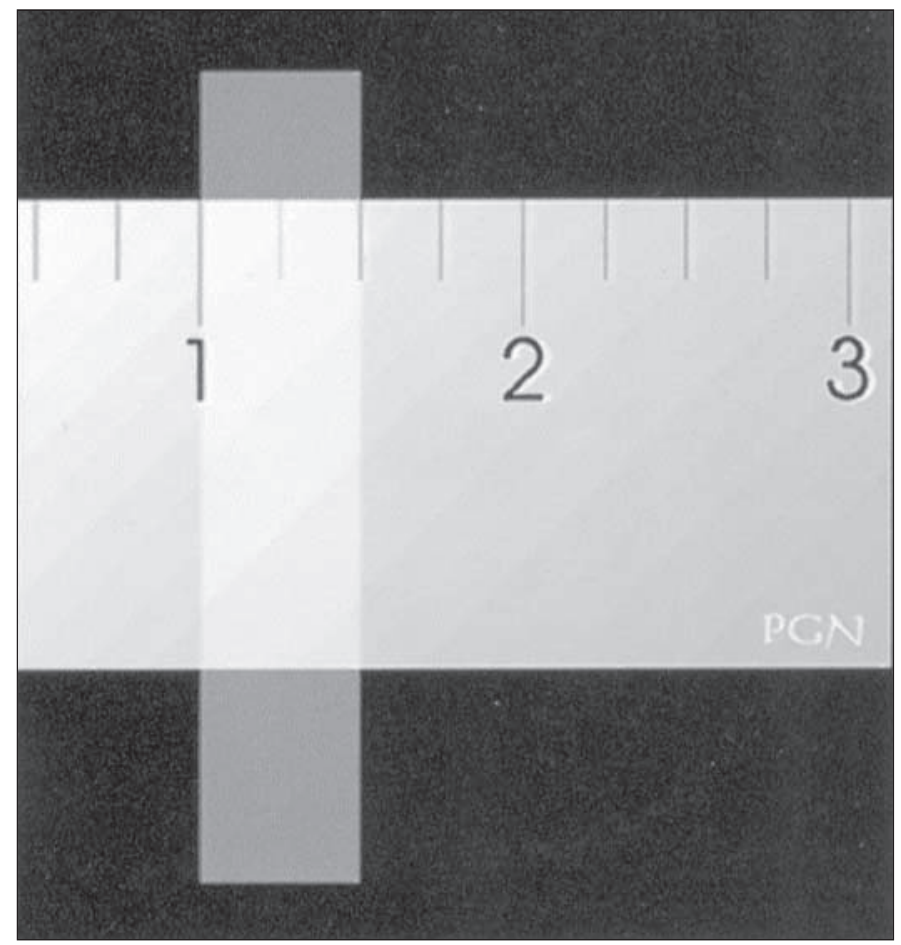

Figura 10 - A largura da faixa é então medida com a ajuda de uma régua

casos, verificou-se que durante a manobra de implantação da lente, a aba superior não se encontrava presente (Grupo A) em $6(5,6 \%)$ olhos, enquanto em outros $4(3,8 \%)$, ela aparecia rasgada ao meio e apenas a metade do lado esquerdo podia ser observada (Grupo B). Nos demais casos (96 olhos - 90,6\%), via-se perfeitamente as duas porções da cápsula anterior (Grupo C) (Tabela 1). 
Em relação ao diâmetro que a pupila apresentava nesse momento, observou-se que ele era pequeno (inferior a $6 \mathrm{~mm}$ ) em todos os casos do Grupo A. Em apenas um caso do Grupo $\mathrm{B}$, ele tinha tal dimensão, nos demais, seu diâmetro era médio (entre 6 e $8 \mathrm{~mm}$ ). Em relação ao Grupo C, o diâmetro foi considerado pequeno em $15(15,6 \%)$ ocasiões; médio, em $50(52,1 \%)$ e grande, em $31(32,3 \%)$.

O espaço deixado livre entre as duas porções da cápsula anterior, foi o último aspecto analisado em relação à etapa peroperatória. A medição da sua largura foi apenas realizada nos últimos 18 (16,5\%) casos. Pôde-se então observar que o tamanho desse espaço definia-se logo após a extração do núcleo, em cerca de 1,5 a 3,0 mm. Não sofrendo qualquer alteração durante os tempos seguintes da cirurgia. Nem mesmo a partir da maneira como o implante havia sido posicionado no interior do saco capsular.

No que se refere ao comportamento das abas da cápsula anterior, notou-se que, durante os primeiros dias do período pós-operatório, tais elementos se apresentavam perfeitamente esticados sobre a lente intra-ocular. Suas bordas apareciam denteadas, em consequiência das puncturas realizadas durante a capsulotomia anterior (Figura 11). Algumas vezes (20 casos $-26,6 \%$ ), essas bordas se apresentavam retas, por terem os seus dentes se dobrando, no decorrer da cirurgia.

Dentro dos primeiros 15 dias pós-operatórios, esses dentes acabavam, de qualquer forma, se dobrando (Figura 12). A partir de então, as bordas começam a se enrolar, tornando-se mais espessas, e acabavam se retraindo em direção à zônula (Figura 13).

Um ano após a cirurgia, quatro diferentes aspectos foram verificados em relação à disposição das abas. $\mathrm{O}$ aspecto que antes caracterizava o Grupo B, não mais foi observado, pois a porção visível da aba superior havia desaparecido. Em compensação, duas novas condições passaram a existir. Numa delas, reunindo $2(1,9 \%)$ pacientes, a aba superior encontravase debaixo do implante e, na outra, com $6(5,7 \%)$ pacientes, as duas abas podiam ser vistas, só que a superior tinha um menor tamanho. Tal aspecto era diferente daquele verificado na maioria dos casos (91 olhos - 85,8\%), em que as duas abas se encontravam simetricamente dispostas sobre o implante. O grupo restante reunia $7(6,6 \%)$ pacientes nos quais não se observava a presença da aba superior (Tabela 2).

As demais alterações sofridas pelo saco capsular, ao longo do primeiro ano pós-operatório, incluíram $12(11,0 \%)$ casos de sinéquia posterior, 34 (31,2\%), de opacificação da cápsula posterior e $3(2,7 \%)$, de enrugamento dessa membrana.

$\mathrm{Na}$ avaliação do posicionamento definitivo das lentes intra-oculares (após 1 ano), foram excluídos 26 (23,8\%) olhos, nos quais a pupila não dilatava adequadamente (14 casos), ou se encontrava distorcida pela presença de sinéquias (12 casos). Os $83(76,2 \%)$ casos restantes foram distribuídos da seguinte forma: Grupo I - perfeitamente centralizada; Grupo II ligeiramente descentralizada (a distância entre a borda da pupila e a borda da lente era menor do que $1 \mathrm{~mm}$ ) e Grupo III descentralizada (tal distância era maior do que $1 \mathrm{~mm}$ ). Esses grupos incluíam, respectivamente, 68 (81,9\%), $11(13,3 \%)$ e 4 $(4,8 \%)$ olhos (Tabela 3$)$.

Quanto ao sentido da descentralização, verificou-se no Grupo II, $2(18,1 \%)$ lentes deslocadas para cima, $4(36,4 \%)$ para o lado direito, $4(36,4 \%)$ para cima e para a direita e $1(9,1 \%)$ para baixo e para a direita. No Grupo III, uma das lentes $(25,0 \%)$ se apresentava deslocada para cima e para a direita,

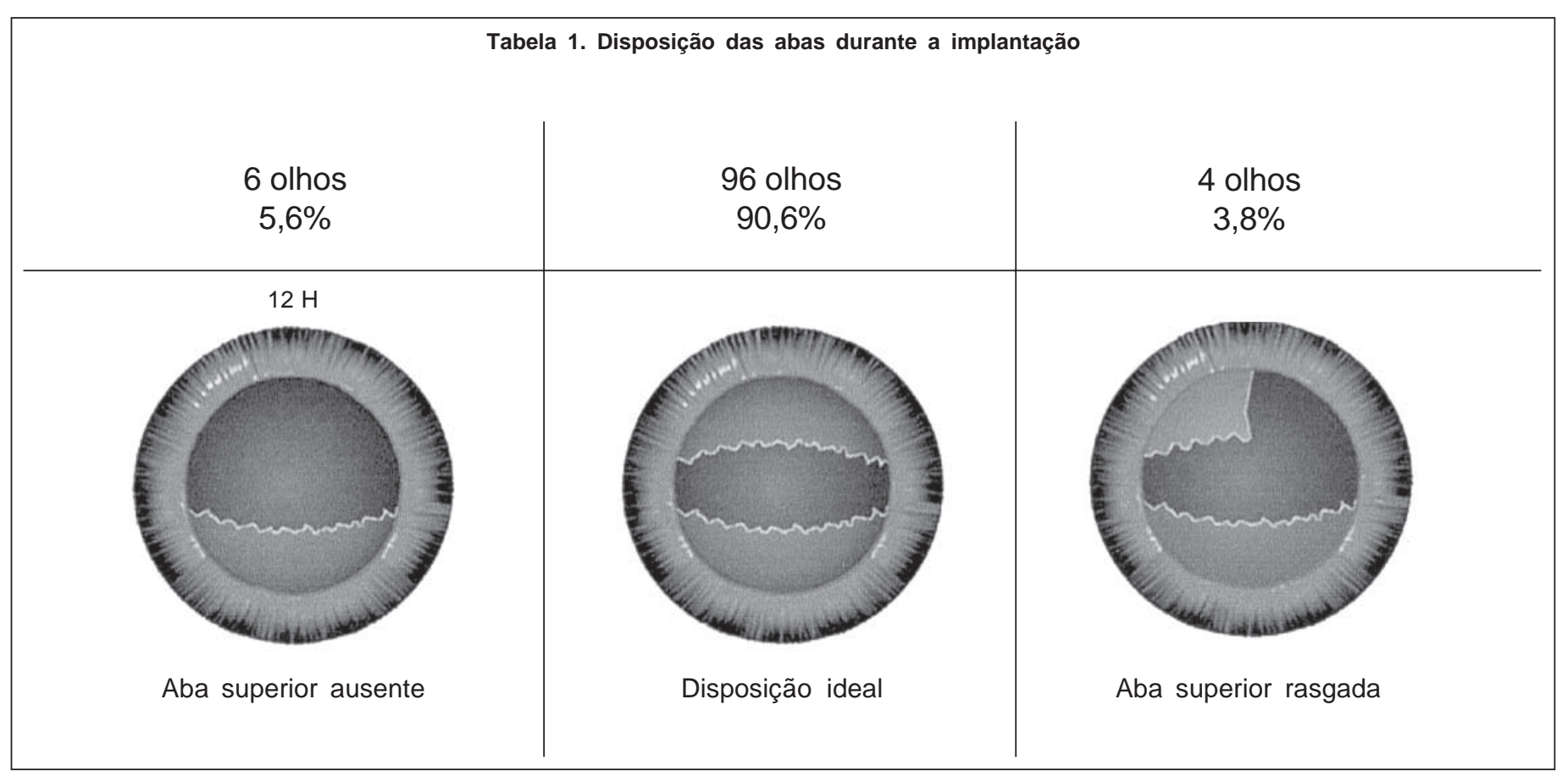




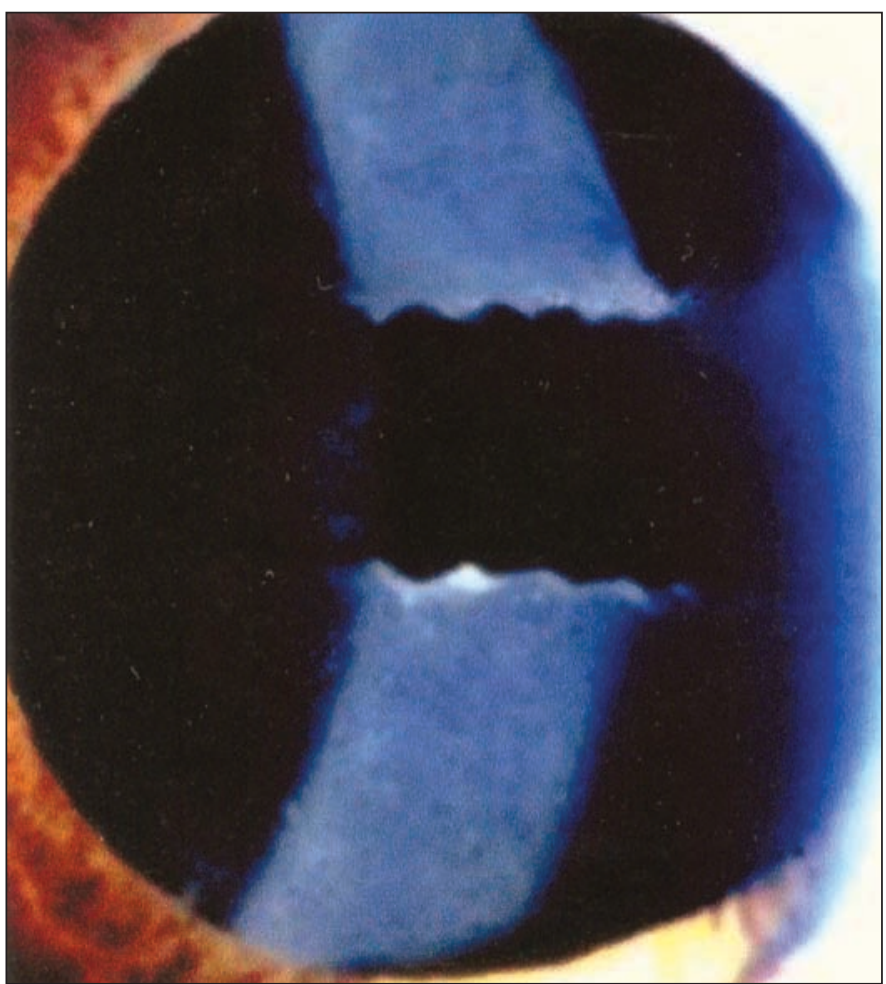

Figura 11 - $24 \mathrm{~h}$ após a cirurgia, as bordas das abas aparecem esticadas e denteadas

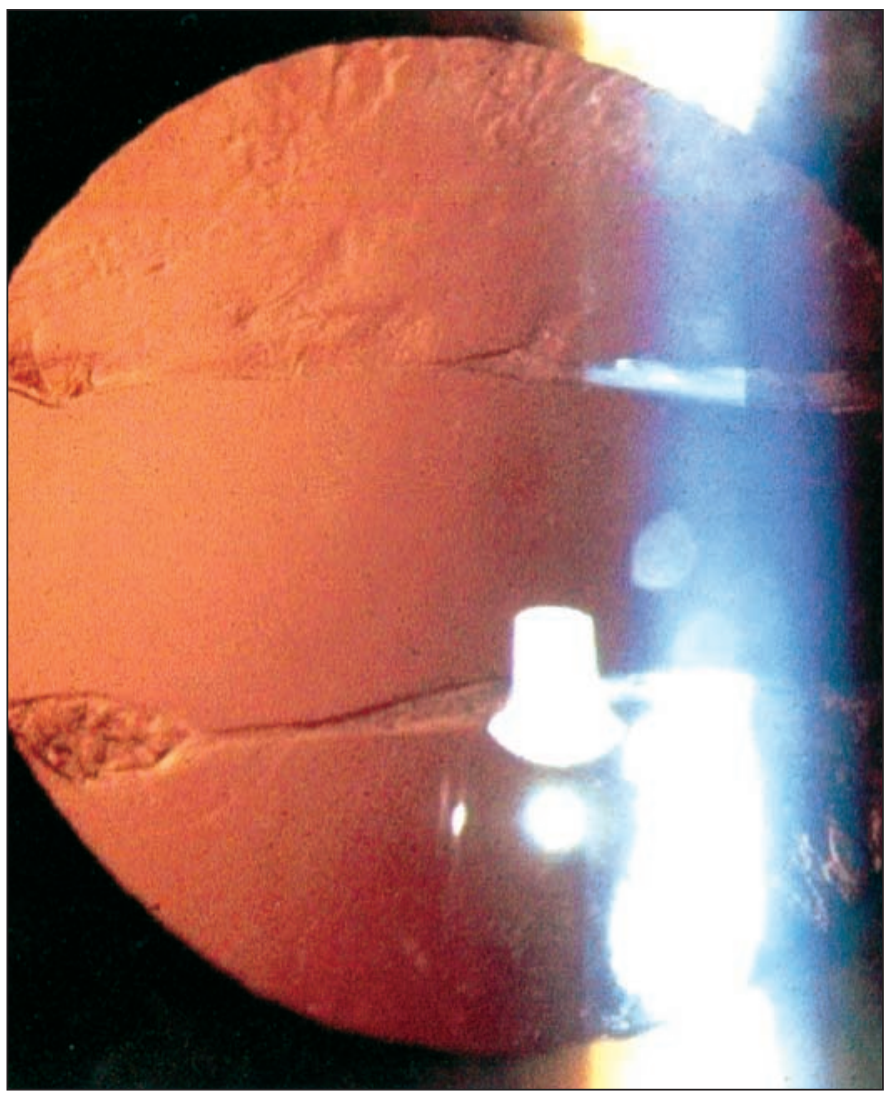

Figura 12 - Dentro dos primeiros 15 dias, as bordas começam a enrolar tornando-se mais espessas

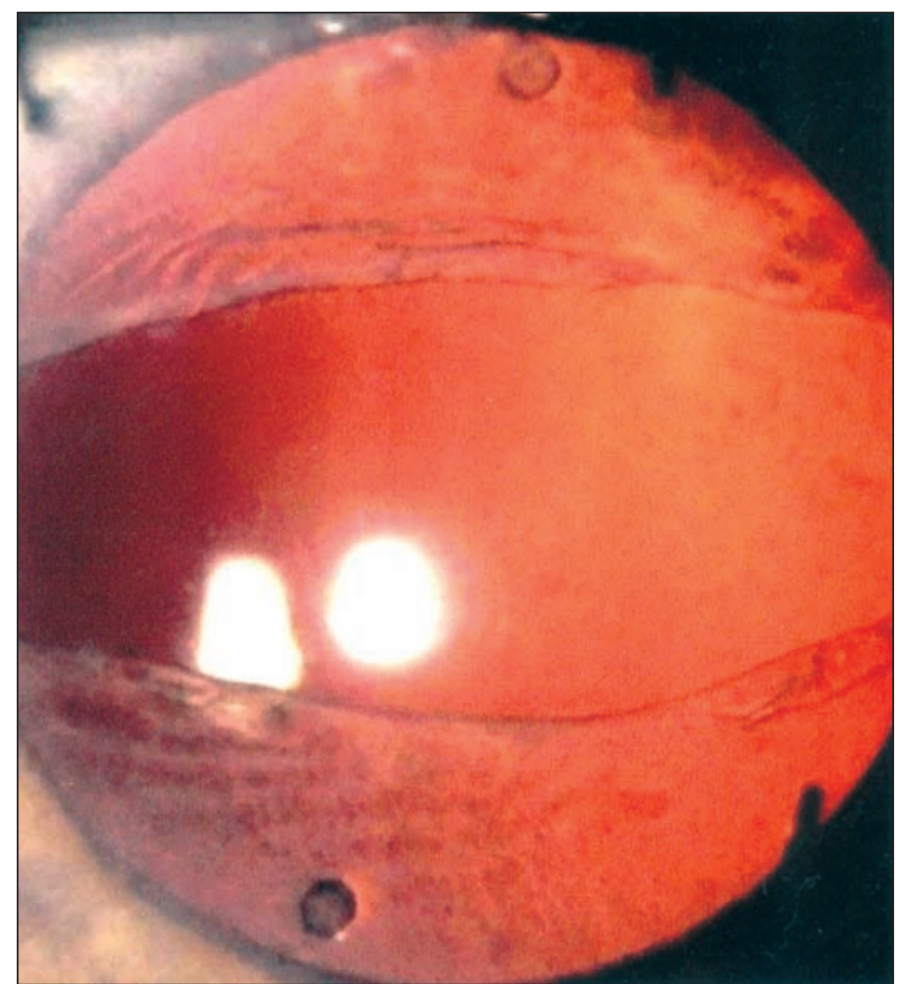

Figura 13 - Com a fibrose do saco capsular as bordas acabam retraindo, aumentando o espaço entre elas

enquanto as outras $3(75,0 \%)$ apareciam desviadas apenas para cima (Tabela 4).

Em relação ao estado da cápsula anterior, por ocasião dessa avaliação, em apenas um caso do Grupo II $(9,0 \%)$ a aba superior não estava visível. Nos demais, pôde-se observar as duas porções de cápsula recobrindo uma extensa parte do implante. Também no Grupo III, a aba superior não foi identificada em apenas um caso $(25,0 \%)$, enquanto em outros dois $(50 \%)$ ela aparecia por debaixo do implante. No último caso desse grupo, a lente se encontrava perfeitamente recoberta pelas abas.

No que se refere aos modelos de lente utilizados nesses casos, havia no Grupo II, $8(72,7 \%)$ implantes de $6 \mathrm{~mm} / 3$ peças, $2(18,2 \%)$ de $7 \mathrm{~mm} / 3$ peças e apenas $1(9,1 \%)$ de $7 \mathrm{~mm} / 1$ peça. No Grupo III, uma das lentes era de $6 \mathrm{~mm} / 3$ peças, outra de 7 $\mathrm{mm} / 3$ peças e as demais de $7 \mathrm{~mm} / 1$ peça. No total dos casos estudados foram implantadas 74 lentes de $7 \mathrm{~mm} / 3$ peças, 13 de $7 \mathrm{~mm} / 1$ peça e 22 de $6 \mathrm{~mm} / 3$ peças (Tabela 5 ).

\section{DISCUSSÃO}

As vantagens da utilização do saco capsular como sítio de implantação das lentes intra-ocular já foram detalhadamente descritas, através de diferentes estudos ${ }^{(14,31-35)}$.

Qualquer garantia que se possa esperar em relação a essa questão, só é realmente alcançada quando, durante implantação, dispõe-se de uma precisa observação dos limites do saco 


Tabela 2. Disposição definitiva das abas (1 ano após a cirurgia)

\begin{tabular}{|c|c|c|}
\hline & Tabela 3. Posicionamento das lentes intra-oculares \\
68 olhos \\
$81,9 \%$
\end{tabular}




\begin{tabular}{|c|c|c|}
\hline $\begin{array}{l}5 \text { olhos } \\
33,3 \%\end{array}$ & $\begin{array}{c}\text { entido do } 0 \\
6 \text { olhos } \\
40,0 \%\end{array}$ & $\begin{array}{l}4 \text { olhos } \\
26,7 \%\end{array}$ \\
\hline Vertical & Oblíquo & Horizonta \\
\hline
\end{tabular}

\begin{tabular}{|llccc|}
\hline \multicolumn{7}{c}{ Tabela 5. Principais caracteristicas dos casos de descentralização da lente intra-ocular } \\
Grau & Sentido & Modelo da LIO & Posição da LIO & Aba superior \\
Grupo II & Oblíquo & $6 \mathrm{~mm} \mathrm{3p}$ & Vertical & Observações \\
Grupo II & Oblíquo & $6 \mathrm{~mm} \mathrm{3p}$ & Vertical & Ausente \\
Grupo II & Oblíquo & $6 \mathrm{~mm} \mathrm{3p}$ & Horizontal & Sobra de córtex às $12 \mathrm{~h}$ \\
Grupo II & Oblíquo & $6 \mathrm{~mm} \mathrm{3p}$ & Vertical & \\
Grupo II & Horizontal & $6 \mathrm{~mm} \mathrm{3p}$ & Vertical & Catarata congênita \\
Grupo II & Horizontal & $6 \mathrm{~mm} \mathrm{3p}$ & Vertical & Ruptura da aba superior \\
Grupo II & Horizontal & $7 \mathrm{~mm} \mathrm{3p}$ & Vertical & Mais curta \\
Grupo II & Horizontal & $7 \mathrm{~mm} \mathrm{1p}$ & Horizontal & Iridotomia radical \\
Grupo II & Vertical & $6 \mathrm{~mm} \mathrm{3p}$ & Horizontal & Ruptura da aba superior \\
Grupo II & Vertical & $6 \mathrm{~mm} \mathrm{3p}$ & Vertical & Ausente \\
Grupo II & Oblíquo & $6 \mathrm{~mm} \mathrm{3p}$ & Vertical & Sob a LIO \\
Grupo III & Vertical & $7 \mathrm{~mm} \mathrm{1p}$ & Horizontal & Ruptura da aba superior \\
Grupo III & Vertical & $6 \mathrm{~mm} \mathrm{3p}$ & Vertical & Sob a LIO \\
Grupo III & Oblíquo & $7 \mathrm{~mm} \mathrm{3p}$ & Horizontal & Ruptura da aba superior \\
Grupo III & Vertical & $7 \mathrm{~mm} \mathrm{3p}$ & \\
\hline
\end{tabular}

capsular. Para tanto, é necessário que a capsulotomia seja realizada de maneira a preservar porções visíveis da cápsula anterior, as quais venham a ser usadas para definir esses limites.

Por conseguinte, qualquer método que se proponha a ser eficiente nesse sentido, não pode deixar a desejar em relação a dois fatores: a garantia de implantação no interior do saco capsular e a adequada fixação do implante a esse nível ${ }^{(18,36)}$.

\section{Garantia de implantação no saco capsular}

Nas técnicas intercapsulares em geral, tal garantia pode ser seriamente comprometida, caso uma das duas porções em que a cápsula anterior é dividida, deixe de ser observada.
Como nos métodos tradicionais a aba superior tem um menor tamanho, não é difícil que venha a desaparecer, após ter sofrido qualquer pequeno dano, ou mesmo, depois de moderada perda da midríase operatória. Com isso, torna-se impossível garantir que a segunda alça do implante, ao ser introduzida às $12 \mathrm{~h}$, vá se posicionar dentro do saco capsular ${ }^{(36)}$.

É bem verdade que, diante de tal circunstância, tem-se a alternativa de implantar a lente horizontalmente, rodando-a durante sua introdução. A aba inferior, graças ao seu avantajado tamanho, pode perfeitamente servir para orientar o caminho da segunda alça até o interior do $\operatorname{saco}^{(37)}$. Não garante, entretanto, que ela venha a se manter perfeitamente alojada dentro desse espaço. Os pedaços de cápsula que passam a 
servir de apoio para suas alças (3 e 9 h), são muito pequenos para evitarem que elas acabem escapulindo em direção ao sulco ciliar ${ }^{(18)}$.

Diante disso, conclui-se que, nessas técnicas, o posicionamento da lente fora do saco capsular pode ocorrer em função de uma imprecisa observação da aba superior (possibilitando a implantação da segunda alça fora do saco capsular), ou devido ao reduzido recobrimento proporcionado pelas porções remanescentes da cápsula anterior (facilitando o escape das alças).

Em tese, portanto, a possibilidade de uma complicação desse tipo torna-se menor, se a abertura da cápsula for feita no centro da área pupilar. Primeiramente, porque o maior tamanho que a aba superior passa a apresentar impede que ela desapareça com tanta facilidade, nas ocasiões em que é rasgada, ou diante de uma contração da pupila. Em segundo lugar, porque a abertura central tem a vantagem de não deixar qualquer porção de cápsula anterior sobre o eixo visual, tornando desnecessária a remoção de parte da aba inferior, após a implantação da lente. Desse modo, não se corre o risco de deixar, através de tal manobra, uma porção muito pequena dessa aba, facilitando o escape de parte do implante.

Tais vantagens vieram a ser de fato comprovadas através das observações desse estudo. Basta dizer que, durante a implantação, as abas de cápsula anterior só deixaram de ser devidamente observadas em $10(9,4 \%)$ ocasiões. Apesar de terem sido registrados 13 casos de ruptura da aba superior e 22 outros nos quais a pupila apresentava, no momento da implantação, um diâmetro inferior a $6 \mathrm{~mm}$. Não querendo dizer que, nas vezes em que a aba superior foi danificada, tenha sido possível proporcionar condições ideais para a fixação do implante.

O mais importante, porém, é que na maioria das vezes $(91,5 \%)$, a lente pode ser observada, ao final da operação, amplamente encoberta pelas duas abas da cápsula anterior. $\mathrm{O}$ que, a princípio, constitui uma garantia de que ela se encontrava dentro do saco pupilar.

É pena que esses aspectos jamais tenham sido avaliados em relação às demais técnicas de capsulotomia anterior, pois, constituem provas irrefutáveis das possibilidades de cada uma delas no sentido de garantir a adequada implantação através da freqüência de implantações assimétricas verificadas em cada um desses métodos. A qual mostrou-se bem menor aqui $(2,7 \%)$ do que nas técnicas intercapsulares tradicionais $(16,6 \% \text { em média })^{(37-38)}$.

\section{Posicionamento da lente intra-ocular}

No que se refere à centralização do implante, o menor tamanho da aba superior pode também influir negativamente, a começar pela razão acima discutida. Sabe-se muito bem que ao ser implantada assimetricamente a lente tende a se deslocar em direção à alça localizada fora do saco capsular ${ }^{(10)}$. A implantação assimétrica não é, entretanto, a única causa de descentralização. Há ocasiões nas quais a lente sai da posição em que foi deixada apesar de se encontrar totalmente dentro do espaço intercapsular ${ }^{(39-40)}$.

Existem fatores relacionados ao processo cicatricial que podem muito bem ocasionar tal tipo de complicação. Nesse processo, as abas se soldam de tal forma à cápsula posterior, que são capazes de produzir, com isso, uma forte pressão sobre a lente intra-ocular ${ }^{(25)}$. É indispensável, portanto, que tais elementos tenham o mesmo tamanho e uma disposição simétrica, para que a pressão exercida sobre o implante não se faça de forma desigual, facilitando seu deslocamento ${ }^{(41-42)}$.

No método intercapsular com a incisão arqueada, a remoção de um pedaço da aba inferior deixa a abertura final com o formato circular. Embora respeite, assim, a questão da simetria, tem a desvantagem de conservar porções muito pequenas das duas abas. $\mathrm{O}$ que, a princípio, poderia vir a facilitar o escape das alças ${ }^{(18,37)}$. Por outro lado, na técnica em que a incisão inicial é reta, a abertura final passa a ter um formato quadrado, proporcionando um recobrimento mais generoso da lente.

Seja como for, é preciso considerar que a posição excêntrica do corte inicial faz com que os pedaços laterais da cápsula anterior se encontrem ligados à aba inferior. Em função disso, podem vir a atuar como uma extensão dessa aba, aumentandolhe o tamanho e, por conseguinte, a força de contração. Juntos, os três pedaços passariam a ter o comportamento semelhante ao de um diafragma se fechando, tal qual ocorre com a capsulorrexis $^{(39)}$. Aqui, porém, a contração do saco não se faria de forma simétrica, justamente por faltar um pedaço do diafragma, correspondente à aba superior. Com isso, a lente pode acabar sofrendo maior pressão inferiormente, e deslocarse em sentido contrário.

Em resumo, a descentralização da técnica intercapsular pode ocorrer em função de um posicionamento assimétrico do implante, ocasionado pela colocação de uma de suas alças fora do saco capsular, ou pela subseqüente luxação desse componente. Pode ainda resultar de uma irregular contração do saco capsular, quando as abas da cápsula anterior apresentam tamanho ou disposição diferentes.

Em relação a esses aspectos, a abertura central parece também apresentar vantagens. Já se viu, por exemplo, que ela é capaz de reduzir a freqüência das implantações assimétricas, sejam elas causadas pela incorreta inserção da lente, ou pelo posterior escape de uma de suas alças. Tão importante quanto isso, porém, é o fato de que a capsulotomia medial dispensa a remoção de qualquer pedaço das abas, depois de concluída a implantação. Desta feita, torna-se praticamente inexistente a possibilidade de virem a ser deixados pedaços com tamanhos ou disposições diferentes. Na realidade, isto só ocorreria, se um desses elementos fosse acidentalmente rasgado durante a operação.

Mais uma vez foi possível comprovar, através das observações aqui feitas, as vantagens desse tipo de capsulotomia. A melhor prova disto foi o expressivo número de casos nos quais a lente se encontrava perfeitamente centralizada, ou deslocada em menos de $1 \mathrm{~mm}(95,2 \%)$. 
Ainda de acordo com as observações do estudo, concluise que as descentralizações se manifestam de forma mais intensa e freqüente nas situações acima descritas. Não poupam, entretanto, os casos nos quais a lente se encontra ampla e simetricamente encoberta pela cápsula anterior. Pela lógica isso jamais deveria ocorrer, a não ser que existisse algum fator capaz de intensificar os efeitos da fibrose, numa determinada porção do saco capsular. Ou então, algum detalhe que pudesse tornar desigual o comportamento das alças, quando submetidas à ação desse processo.

Para alguns, existe de fato certa interferência sobre a contração capsular, por parte de restos corticais e células do epitélio cristaliniano. Segundo eles, a presença desses elementos pode fazer com que a porção do saco em que estão localizados se contraia de forma mais intensa ${ }^{(35,43)}$. Também em relação ao comportamento das alças, existe a hipótese de que, em função de um defeito do material ou perda da sua memória, elas possam tornar-se menos resistentes à pressão exercida pela fibrose capsular. Podem ainda ser deformadas pelo excessivo emprego de força durante a manobra de implantação ${ }^{(18)}$.

\section{CONCLUSÃO}

Enfim, os resultados aqui obtidos indicam que a capsulotomia medial poder ser uma boa alternativa para a implantação intercapsular. Na extração do núcleo, por exemplo, as dificuldades encontradas tiveram muito mais a ver com a incompleta dissecção das adesões corticais, do que com o tamanho das abas. Quanto ao difícil acesso ao córtex de 12 h, não se pode considerar uma novidade, já que o mesmo ocorre quando se faz uso da capsulorrexis.

\section{ABSTRACT}

Purpose: To evaluate the benefits of an alternative technique of anterior capsulotomy created to guarantee the complete implantation of the IOL in the capsular bag, during extracapsular cataract extraction. Methods: One hundred and nine eyes were operated on through this technique and followed during a period of 1 year. The possibilities of the technique were evaluated regarding two aspects: the guarantee of a perfect placement of the IOL in the capsular bag and ability of providing an effective fixation of the implant through the characteristics of the anterior capsule remains. The first aspect was analyzed considering the number of cases where the two flaps could be properly observed during the implantation. The second aspect was evaluated through the positioning of the lens after 1 year. Specific difficulties and complications of this technique were also investigated. Results: The two flaps could be properly observed during the implantation in 96 $(90.6 \%)$ cases. One year after the surgery, the lens was centered in $81.9 \%$ of the cases, slightly off the center (less than $1 \mathrm{~mm}$ ) in $13.3 \%$ and off the center (more than $1 \mathrm{~mm}$ ) in
4.8\%. Conclusion: These results, if compared to those presented in relation to other types of capsulotomy, indicate that this technique is a good alternative to provide the appropriate implantation of the lens in the bag, in extracapsular cataract extraction.

Keywords: Cataract extraction; Intraocular lens implantation; Capsulotomy; Intercapsular; In the bag; Cataract, capsule, lens; Implantation, implant, intraocular; Visual disorders

\section{REFER̂̂NCIAS}

1. MansChot WA. Histopathology of eyes containing Binkhorst lenses. Am J Ophthalmol. 1974;77(6):865-71.

2. Shearing SP. Evolution of the posterior chamber intraocular lens. J Am Intraocul Implant Soc. 1984;10(3):343-6.

3. Apple DJ, Cameron JD, Lindstrom RL. Loop fixation of posterior chamber intraocular lenses. Cataract. 1984;2(1):7-10.

4. Apple DJ, Park SB, Merkley KH, Brems RN, Richards SC, Langley KE, et al. Posterior chamber intraocular lenses in a series of 75 autopsy eyes. Part I : Loop location. J Cataract Refract Surg. 1986;12(4):358-62.

5. Brems RN, Apple DJ, Pfeffer BR, Park SB, Piest KL, Isemberg RA. Posterior chamber intraocular lenses in a series of 75 autopsy eyes. Part III : Correlation of positioning holes and optics edges with pupillary aperture and visual axis. J Cataract Refract Surg. 1986;12(4):367-71.

6. Park SB, Brems RN, Parsons MR, Pfeffer BR, Isemberg RA, Langley KE, et al. Posterior chamber intraocular lenses in a series of 75 autopsy eyes. Part II: Postimplantation loop configuration. J Cataract Refract Surg. 1986;12(4):363-6.

7. Hansen SO, Tetz MR, Solomon KD, Borup MD, Brems RN, O'Morchoe $\mathrm{DJC}$, et al. Decentration of flexible loop posterior chamber intraocular lenses in a series of 222 postmortem eyes. Ophthalmology. 1988;95(3):344-9.

8. Nicholson DH. Occult iris erosion: a treatable cause of recurrent hyphema in iris supported intraocular lenses. Ophthalmology. 1982;89(2):113-20.

9. Margargal LE, Goldberg RE, Uram M, Gonder JR, Brown GC. Recurrent microhyphema in the pseudophakic eye. Ophthalmology. 1983;90(10):1231-4.

10. Apple DJ, Kincaid MC. Histopathology of intraocular lens explantation. Cataract. 1985;2(1):7-11.

11. Johnson SH, Kratz RP, Olson PF. Iris transillumination defect and microhyphema syndrome. J Am Intraocul Implant Soc. 1984;10(4):425-8.

12. Woodhams JT, Lester JC. Pigmentary dispersion glaucoma secondary to posterior chamber intraocular lenses. Ann Ophthalmol. 1984;16(9):852-5.

13. Masket S. Pseudophakic posterior iris chafing syndrome. J Cataract Refract Surg. 1986;12(3):252-6.

14. Miyake K, Asakura M, Kobayashi H. Effect of intraocular lens fixation on the blood-aqueous barrier. Am J Ophthalmol. 1984;98(4):451-5.

15. Sanders DR, Kraff MC, Lieberman HL, Peyman GA, Tarabishy S. Breakdown and reestablishment of blood-aqueous barrier with implant surgery. Arch Ophthalmol. 1982;100(4):588-90.

16. Obstbaum SA, Galin MA. Cystoid macular edema and ocular inflammation: the corneo-retinal inflammatory syndrome. Trans Ophthalmol Soc UK. 1979;99 (1): $187-91$.

17. The first international cystoid macular edema symposium. Surv Ophthalmol. 1984;28 (suppl):131-620.

18. Apple DJ, Mamalis N, Olson RJ, Kincaid MC. New concepts in intraocular lens implantation. In: Apple DJ. Intraocular lenses: evolution, designs, complications and pathology. Baltimore: Williams \& Wilkins; 1989. p.175-221.

19. McIntyre DJ. Manual extracapsular cataract technique. In: Stark WJ, Terry AC, Maumenee AE. Anterior segment surgery: IOLs, lasers and refractive keratoplasty. Baltimore: Williams \& Wilkins; 1987. p.141-8.

20. Sheets JH, Maida JW. Lens glide in implant surgery. Arch Ophthalmol. 1978; 96(1):145-6.

21. Clayman HM. Technique for insertion of the superior loop of the Shearingstyle posterior chamber lens. J Am Intraocul Implant Soc. 1980;6(4):383-4.

22. Lyle WA. A new phacoemulsification technique for in-the-bag IOL placement. J Am Intraocul Implant Soc. 1983;9(4):461-3.

23. Lewicky AO, Lewis NZ, Horn G, Petkus RW, Lopez OI, Stillerman ML, et al. An insertion technique for the double-closed-loop posterior chamber lens. J Am Intraocul Implant Soc. 1984;10(2):226-8. 
24. Barnet RW. In-the-bag placement of posterior chamber lenses. J Am Intraocul Implant Soc. 1985;11(3):294-6.

25. Bates RA. In-the-bag posterior chamber lens implantation. J Am Intraocul Implant Soc. 1988;14(6):670-3.

26. Kietzman B. More assured in-the-bag placement of C-loop posterior chamber intraocular lenses. Ophthalmic Surg. 1989;20(6):403-5.

27. Pallin SL, Walman GB. Posterior chamber lens insertion using Healon to position capsular flaps. J Am Intraocul Implant Soc. 1981;7(3):270.

28. Miller D, Stegmann R. Use of sodium hyaluronate in human IOL implantation. Ann Ophthalmol. 1981;13(7):811-5.

29. Galand A. L'insertion d'un implant dans le dac capsulaire. Bull Soc Belge Ophtalmol. 1982;198(2):55-62.

30. Baikoff G. Insertion of the Simcoe posterior chamber lens into the capsular bag. J Am Intraocul Implant Soc. 1981;7(3):267-9.

31. Eifrig DE, Doughman DJ. Intraocular plastic lens loop fixation in the rabbit Arch Ophthalmol. 1976;94(7):1167-8.

32. Binkhorst CD. Five hundred planned extracapsular extractions with iridocapsular and iris clip lens implantation in senile cataract. Ophthalmic Surg. 1977;8(3):37-44

33. Juechter KB. Histopathology of capsule-fixated intraocular lenses. In: Emery JM. Current concepts in cataract surgery. Selected proceedings of the fifth biennial cataract surgery congress. St. Louis: C.V. Mosby; 1978. p.165-72

34. Irvine AR. Extracapsular cataract extraction and pseudophakos implantation in primates: clinic-pathologic study. Ophthalmic Surg. 1981;12(1):27-38.

35. Apple DJ, Reidy JJ, Googe JM, Mamalis N, Novak LC, Loftfield K, et al. A comparison of ciliary sulcus and capsular bag fixation of posterior chamber intraocular lenses. J Am Intraocul Implant Soc. 1985;11(1):44-63.

36. Kraff MC. Implant loops: In or out of the bag? In: Stark WJ, Terry AC, Maumenee AE. Anterior segment surgery: IOLs, lasers and refractive keratoplasty. Baltimore: Williams \& Wilkins; 1987. p.153-7.

37. Condon PI, Barret GD, Kinsella M. Results of the intercapsular technique with IOGEL lens. J Cataract Refract Surg. 1989;15(5):495-503.

38. Naylor G, Sutton GA, Morrel AJ, Pearce JL. Intercapsular versus extracapsular cataract extraction. Ophthalmic Surg. 1989;20(11):766-8.

39. Gimbel HV, Neuhann T. Development, advantages and methods of the continuous circular capsulorhexis technique. J Cataract Refract Surg. 1990;16(1): 31-7. Comment on: J Cataract Refract Surg. 2001;27(9):1346-7.

40. Davison JA. Analysis of capsular bag defects and intraocular lens positions for consistent centration. J Cataract Refract Surg. 1986;12(2):124-9.

41. Fritch CD, Zirm M, Dillman D, Crozafon P, Nordan L. Intraocular lens design. In: Nordan L, Maxwell WA, Davison JA. The surgical rehabilitation of vision. London: Gower Medical; 1992. p.8.1-8.26.

42. Colvard DM, Dunn SA. Intraocular lens centration with continuous tear capsulotomy. J Cataract Refract Surg. 1990;16(3):312-4.

43. Nishi O. Intercapsular cataract surgery with lens epithelial cell removal. Part I: without capsulorhexis. J Cataract Refract Surg. 1989;15(3):297-300.

\section{Congresso dos Centros de Ensino em Oftalmologia do Paraná e Reunião do Capífulo Brasileiro da Associação Pan-americana de Oftalmologia}

\section{8 a 20 de Novembro de 2.004 Curitiloa - PR}

